\title{
Effects of Socioeconomic Status and Social Support on Well-being
}

\author{
Xiaoyuan $\mathrm{Chu}^{1}$, Yuan $\mathrm{Li}^{2}$, Zhenyu $\mathrm{Li}^{3}$ \& Jing $\mathrm{Han}^{1}$ \\ ${ }^{1}$ School of Economics and Resource Management, Beijing Normal University, Beijing, China \\ ${ }^{2}$ Research Department, CIConsulting, Shenzhen, China \\ ${ }^{3}$ Business School, Beijing Normal University, Beijing, China \\ Correspondence: Xiaoyuan Chu, School of Economics and Resource Management, Beijing Normal University, Beijing, \\ China. Tel +8613126756090
}

Received: July 16, 2015

Accepted: July 29, 2015

Available online: July 31, 2015

doi:10.11114/aef.v2i3.995

URL: http://dx.doi.org/10.11114/aef.v2i3.995

\begin{abstract}
Based on the theoretical analysis, with first-hand data collection and using multiple regression models, this study explored the relationship between social support, socioeconomic status and well-being. We draw on the following conclusions: (1) Family support and general support of others have positive influences on general well-being. And these influences largely remain constant for the sampled subjects regardless of their socioeconomic status. (2) One dimension of socioeconomic status (family annual income) has a positive influence on general well-being. But in consideration of the social support and interaction terms of socioeconomic status and social support, this influence is no longer significant.
\end{abstract}

Keywords: Social Support; Socioeconomic Status; Well-being

\section{Introduction}

Well-being plays a vital role for people's health. It benefits an individual in health, life span (Diener \& Chan, 2011), work, income and interpersonal relationship (Diener \& Ryan, 2009). Social support is one of the most important predictive variables for well-being. Empirical researches (Kahn, Hessling, \& Russell, 2003; Nahum-Shani, Bamberger, \& Bacharach, 2011; Silverstein \& Bengtson, 1994), theoretical analysis (Cohen \& Syme, 1985; Davis, Morris, \& Kraus, 1998; Taylor, 2011) as well as meta-analysis (Chu, Saucier, \& Hafner, 2010) have proved the significant predictive effect of social support on subjective well-being, although there is some disagreement on whether the effect is direct or indirect (Bal, Crombez, van Oost, \& Debourdeaudhuij, 2003; Gençöz, Özlale, \& Lennon, 2004).

Family socioeconomic status mainly refers to the hierarchical ranking of a family in education, property, social status and other valuable resources (Lancee,2010; Lease \& Dahlbeek, 2009). As to the composition of socioeconomic status, different scholars have different views: Some believed that socioeconomic status includes four dimensions, namely occupation, income, housing and resident region (Warner, 1949). Some designed the two-factor social status index on the basis of occupation and education (Hollingshead, 1957). And based on the data from the American general social survey in 1950, Duncan designed an index which took occupational prestige, income and education into consideration (Duncan, 1967). Afterwards, Green developed two indexes, both of which took family income and education into consideration and one of them also considered occupation (Green, 1970). Moreover, Kuppuswamy designed a scale to measure the three elements of socioeconomic status - family income, individual degree of education and occupational status (Kuppuswamy, 1981). Meanwhile some other researchers hold different opinions on the composition of socioeconomic status, such as seven dimensions (housing, ownership of properties, degree of education, occupation, monthly income, land, social participation, Tiwari, et al, 2005) or three dimensions (physical capital, human capital and social capital, Oakesa \& Rossib, 2003). According to the history of development of socioeconomic status index and the mainstream opinion of current research mentioned-above, we would take the traditional opinion to calculate socioeconomic status index, whose dimension includes occupation, income and degree of education.

Measurement on student's socioeconomic status can be traced back to the establishment of social stratification model established by Blau and Duncan, in which two dimensions, father's occupation and degree of education, are taken to predict child's academic and occupational achievement (Blau \& Duncan, 1967). And Haller and Portes improved the model with two more dimensions, mother's degree of education and family income, taken into consideration (Haller \& 
Portes, 1973). Most of researches carried out thereafter took parents' degree of education, occupation and income as dimensions for student's socioeconomic status index.

An individual is affected by his/her socioeconomic status in many aspects (Jing et al, 2014). And the researches on the relationship between socioeconomic status and well-being mainly focus on the income and well-being, the results of which disagree with each other mainly owing to different measuring methods applied (Lowry, 1984; George et al, 1985; Graham, 2005; Ryan \& Colleen, 2008). For instance, some found income has not much to do with well-being (Headey \& Wearing, 1992; King \& Napa, 1998; Ng, 1997), while other indicated there is a strong positive correlation between wealth and well-being (Diener et al., 1995; Diener \& Fujita, 1995; Cummins, 1998; Schyns, 1998; Martin \& Silvia, 2000; Hayo, 2003). There is much disparity in the conclusions of studies on relationship between education and well-being (Catherine \& Marieke, 1997). Some research done in China indicated that the more education one received, the higher he /she is in well-being. But once income is taken into consideration as a control variables, the more education one received, the lower he/she is in well-being (Liu Wenmin \& Wu dan, 2011). Research conducted by Luo Chuliang also confirmed this conclusion, and further discovered it is income that explains the positive correlation between education and well-being (Luo Chuliang, 2006).

On the basis of previous studies, this study attempts to use high school students as subjects, investigating the relationship among the socioeconomic status, social support and well-being, trying to discover underlying mechanisms.

In order to reveal the relationship between well-being, socioeconomic status and social support, this paper constructed a basic model as follows:

$$
G W B_{i}=\beta_{0}+\sum \lambda_{1 j} S E S_{j i}+\sum \lambda_{2 k} S S_{k i}+\sum \lambda_{3 J k} S E S_{j i} * S S_{k i}+\varepsilon_{i}
$$

In the formula, $\mathrm{i}$ represents the subjects, $\mathrm{j}$ represents the dimension of socioeconomic status, $\mathrm{k}$ represents the dimension of social support, GWB represents the general well-being, SES represents Socioeconomic Status (with five dimensions: father's degree of education; mother's degree of education; family annual income; father's occupation and mother's occupation;), SS represents social support (with three dimensions: family support; peer support and general support of others), and $\varepsilon \mathrm{i}$ is the error term.

\section{Research Methods}

\subsection{Subjects}

Cluster sampling methods were used for the investigation. 600 questionnaires were distributed to high school students aged 12 - 18 from two senior high schools chosen in Beijing, with 541 questionnaires returned and 520 valid (male 226, female 294). The valid response rate is 86.67 .

\subsection{Research Instrument}

The definitions of variables and data sources are shown in table 1. Specific measuring tools are as follow:

Socioeconomic Status: the index of family SES is often measured by parents' occupation, degree of education and family income. With reference to previous studies, this research applied a self-designed self-reporting questionnaire which divided parents' occupation into 5 grades, parents' degree of education into 6 grades and family income into 6 grades.

Social Support: This research used social support appraisals (SS-A) scale (made by Vaux et al., and revised by (Xin, Chi, Geng, Zhao \& Wang, 2007) to measure social capital. 20 items in total in this scale respectively measured family or family member support, peer support and general support of others. 0.91 is the coefficient of the whole scale, in which $0.84,0.81$ and 0.83 are respectively the coefficients of family support ( 7 items), peer support ( 7 items), general support of others.

Well-being: Well-being is measured by General Well-being Schedule, which is developed by American National Center for Health Statistics to evaluate happiness. This schedule consists of 33 items, and the higher the score is, the more intense of happiness the one felt. This survey reserved 20 items in consideration of the circumstances of Chinese teenage test-takers.

Table 1. Definitions of variables and data sources

\begin{tabular}{lcccr}
\hline Variable & Name & Operational Definition & scale & dimension \\
\hline $\begin{array}{l}\text { Explained variables } \\
\text { Explanatory }\end{array}$ & GWB & General well-being scale score & General well-being Scale & null \\
$\begin{array}{l}\text { variables } \\
\begin{array}{l}\text { Explanatory } \\
\text { variables }\end{array}\end{array}$ & SES & SES $=(\mathrm{FE}+\mathrm{ME}+2 *$ FAI & Self-designed & FE; ME; FAI; \\
& & $\mathrm{SS}=(\mathrm{FS}+\mathrm{PS}+\mathrm{GSO}) / 3$ & Social support appraisals & FS; PS; GSO \\
\hline
\end{tabular}


Description: SES is short for socioeconomic status; FE is short for father's score of degree of education; ME is short for mother's score of degree of education; FAI is short for score of family annual income; FO is short for father's occupation; $\mathrm{MO}$ is short for mother's occupation; SS is short for score of social support; FS is short for score of family support; PS is short for score of peer support; GSO is short for General support of others. GWB is short for general well-being. The same below.

\subsection{Research Process}

The questionnaires were administrated with the unified instructions. And the questionnaires, with no time limitation, were collected on the spot and checked one by one with invalid ones eliminated. This research employed SPSS19.0 for statistical analysis, which includes analysis of variance, correlation analysis and analysis of regression.

\section{Results}

\subsection{Reliability of the Questionnaire}

We undertook item analysis to calculate the reliability of the questionnaire/ scale for socioeconomic status, social support and well-being and the coefficient Cronbach $\alpha$ is in table 2 as below:

The data in table 2 shows that all the three questionnaires of socioeconomic status, social support and well-being are reliable with reliability above 0.8 .

\subsection{Correlation analysis}

Pearson's correlation was applied to calculate the correlation coefficients of the socioeconomic status as well as its dimensions, social support as well as its dimensions and well-being. The result in table 2 shows there is a significantly positive correlation between social support along with its dimensions and well-being, and the correlation coefficients are between 0.285 to 0.392 (correlation coefficient between social support total score and well-being is 0.392 ), which means that social support is significantly positively correlated to well-being. As for the relationship between socioeconomic status and well-being, the result indicates that only family annual income is significantly related to well-being.

Table 2 Correlation coefficients and Cronbach's Alpha of the SES, SS and GWB

\begin{tabular}{lcccccccccc}
\hline & SES & FE & ME & FAI & FO & MO & SS & PS & FS & $\begin{array}{c}\text { GSO } \\
\text { Cronbach's } \alpha\end{array}$ Item \\
No.
\end{tabular}

Description: **. Correlation is significant at the 0.01 level (2-tailed). *. Correlation is significant at the 0.05 level (2-tailed).

\subsection{Regression Analysis of Social Support on Well-being}

To better understand the impact of social support on the well-being, we conducted a regression analysis, with well-being as predicted variable and social support as predictive variable. The study selected stepwise regression as the method at first. The regression results are shown in Table 3.

Table 3 Stepwise Regression Analysis of Social Support on Well-being

\begin{tabular}{lcccc}
\hline Predictive variable & Standardized $\beta$ & $\mathrm{T}$ & $\mathrm{P}$ & Adjusted R \\
\hline (Constant) & & 14.224 & .000 & .166 \\
GSO & .291 & 5.655 & .000 & \\
FS & .161 & 3.143 & .002 & \\
\hline
\end{tabular}

As shown in Table 3: General support of others and family support entered into the regression equation on well-being, with a predictive power of $16.6 \%$;

And we also conducted a forced entry regression analysis with well-being as predicted variable and social support as predictive variable to better understand the effect of all the dimensions of social support on well-being. The regression 
results are shown in Table 4.

Table 4 Forced Entry Regression Analysis of Social Support on Well-being

\begin{tabular}{lcccc}
\hline Predictive variable & Standardized $\beta$ & $\mathrm{T}$ & $\mathrm{P}$ & Adjusted $\mathrm{R}^{2}$ \\
\hline (Constant) & & 14.143 & .000 & .166 \\
FS & .163 & 3.166 & .002 & \\
PS & -.075 & -1.141 & .254 & \\
GSO & .350 & 4.794 & .000 & \\
\hline
\end{tabular}

The result is similar to that of stepwise regression, with general support of others and family support entered into the regression equation on well-being.

\subsection{Regression Analysis of Social Support on Well-being}

To better understand the impact of socioeconomic status on the well-being, we conducted a regression analysis, with well-being as predicted variable and socioeconomic status as predictive variable. The study selected stepwise regression as the method at first. The regression results are shown in Table 5.

Table 5 Stepwise Regression Analysis of Socioeconomic Status on Well-being

\begin{tabular}{lcccc}
\hline Predictive variable & Standardized $\beta$ & $\mathrm{T}$ & $\mathrm{P}$ & Adjusted $^{2}$ \\
\hline (Constant) & & 48.203 & .000 & .008 \\
FAI & .097 & 2.219 & .027 & \\
\hline
\end{tabular}

As shown in Table 5: family annual income entered into the regression equation on well-being, with a predictive power of $0.80 \%$;

And we also conducted a forced entry regression analysis with well-being as predicted variable and socioeconomic status as predictive variable to better understand the effect of all the dimensions of socioeconomic status on well-being. The regression results are shown in Table 6.

Table 6 Forced Entry Regression Analysis of Socioeconomic Status on Well-being

\begin{tabular}{lcccc}
\hline Predictive variable & Standardized $\beta$ & $\mathrm{T}$ & $\mathrm{P}$ & Adjusted $\mathrm{R}^{2}$ \\
\hline (Constant) & & 34.223 & .000 & .004 \\
FE & -.001 & -.020 & .984 & \\
ME & .043 & .619 & .536 & \\
FAI & .118 & 2.331 & .020 & \\
FO & -.048 & -.816 & .415 & \\
MO & -.040 & -.665 & .506 & \\
\hline
\end{tabular}

The result is similar to that of stepwise regression, with family annual income entered into the regression equation on well-being.

\subsection{Regression Analysis of Social Support and Socioeconomic Status on Well-being}

In order to further reveal the effect of socioeconomic status and social support on the well-being, we conducted a regression analysis, with well-being as the predicted variable, and socioeconomic status as well as social support as the predictive variables. The results are shown in Table 7 and 8.

Table 7 Stepwise Regression Analysis of Social Support and Socioeconomic Status on Well-being

\begin{tabular}{lcccc}
\hline Predictive variable & Standardized $\beta$ & $\mathrm{T}$ & $\mathrm{P}$ & Adjusted $\mathrm{R}^{2}$ \\
\hline (Constant) & & 14.224 & .000 & .166 \\
GSO & .291 & 5.655 & .000 & \\
FS & .161 & 3.143 & .002 & \\
\hline
\end{tabular}

Table 8 Forced Entry Regression Analysis of Social Support and Socioeconomic Status on Well-being

\begin{tabular}{lcccc}
\hline Predictive variable & Standardized $\beta$ & $\mathrm{T}$ & $\mathrm{P}$ & Adjusted $\mathrm{R}^{2}$ \\
\hline (Constant) & & 13.831 & .000 & .166 \\
FS & .165 & 3.202 & .001 & \\
PS & -.069 & -1.045 & .297 & \\
GSO & .356 & 4.863 & .000 & \\
SES & -.044 & -1.046 & .296 & \\
\hline
\end{tabular}

As shown in Table 7 and 8, in consideration of the socioeconomic status, family support and general support of others are still significant in the regression model of well-being. And socioeconomic status is not a significant predictor for well-being. 
To further understand the combined effect of socioeconomic status and social support on the well-being, we conducted a regression analysis, with well-being as the predicted variable, socioeconomic status and social support as well as the interaction terms of socioeconomic status and social support as the predictive variables. The results are shown in Table 9.

Table 9 Stepwise Regression Analysis of Social Support, Socioeconomic Status and the Interaction Terms on Well-being

\begin{tabular}{lcccc}
\hline Predictive variable & Standardized $\beta$ & $\mathrm{T}$ & $\mathrm{P}$ & Adjusted $\mathrm{R}^{2}$ \\
\hline (Constant) & & 14.224 & .000 & .166 \\
GSO & .291 & 5.655 & .000 & \\
FS & .161 & 3.143 & .002 & \\
\hline
\end{tabular}

As shown in Table 9, in consideration of the socioeconomic status and interaction terms, family support and general support of others have positive influences on general well-being. And these influences largely remain constant for the sampled subjects regardless of their socioeconomic status.

\section{Discussion}

It is found in this study that both family support and general support of others have significant predictive effects on general well-being, which largely remains constant for the sampled subjects regardless of their socioeconomic status. This conclusion is consistent with former research conclusions on the effect of social support on subjective well-being: social support and subjective well-being are positively related. And this relationship would not change for subjects with different socioeconomic status. Social support system helps to reduce various pressures, burnout and other negative emotions as well as generate positive and optimistic emotions. Besides, social support also helps to relieve loneliness and increase well-being. One can deal with the pressure more effectively with a comprehensive and sound social support system, which in turn leads to a happier life.

As we found in this study, social support from both family and general others can raise the well-being. Family members are the most intimate for most people. Interaction with family members is more important than interaction with others (such as colleagues, classmates, friends etc.) in the sense of frequency, extent or depth. As a result, how much support an individual could get from his family influences his well-being significantly. And general social support of others is the general judgment of an individual for the relationship between him and the society as well as general others. It reflects an individual's underlying view of human nature and his self-identity. In General, the individual who perceives more general support of others holds a more positive and optimistic attitude towards human nature, trusts others more, and has better sense of security. It explains why t general support of others predicts well-being. Furthermore, as we found in this study, the influence of family support and general support of others on well-being can be found in individuals with various socioeconomic statuses. In other words, family support works in the same way for individual with high socioeconomic status as well as with low socioeconomic status. So does general support of others. And we did not find the effect of peer support on well-being in this study. One possible reason is that we took the sample from high school students, most of who still live with their parents or other family members. Consequently, the effect of peer support to well-being is not fully displayed.

Another discovery in this research is that socioeconomic status does not have a significant effect on well-being when social support is taken into consideration. Without consideration of social support, it is found that family income has some influence on children's well-being, while parents' degree of education and occupation do not. However, when social support is taken into consideration, the influence of family income becomes insignificant. This implies that socioeconomic status may influence well-being through social support.

\section{Conclusion}

1. Family support and general support of others have positive influences on general well-being.

2. And these influences largely remain constant for the sampled subjects regardless of their socioeconomic status.

3. One dimension of socioeconomic status (family annual income) has a positive influence on general well-being.

4. But in consideration of the social support and interaction terms of socioeconomic status and social support, this influence is no longer significant.

\section{References}

Bal, S., Crombez, G., van Oost, P., \& Debourdeaudhuij, I. (2003). The role of social support in well-being and coping with self-reported stressful events in adolescents. Child Abuse \& Neglect, 27(12), 1377-1395. http://dx.doi.org/10.1016/j.chiabu.2003.06.002

Blau P, Duncan O D. The American Occupational Structure [R]. New York: Wiley. 1967. http://dx.doi.org/10.2307/2092399 
Catherine, R., \& Marieke, W. (1997). Education and Subjective Quality of Life [J]. Journal of Health and Social Behavior, 9, 275-297. http://dx.doi.org/10.2307/2955371

Chu, P. S., Saucier, D. A., \& Hafner, E. (2010). Meta-analysis of the relationships between social support and well-being in children and adolescents. Journal of Social and Clinical Psychology, 29(6), 624-645. http://dx.doi.org/10.1521/jscp.2010.29.6.624

Chu,X. Y., Li, Z. Y., Yan, B. L., Han, J., \& Fan, F. Q. (2015) Comparative Study of Regular and Vocational High School Students on Family Socioeconomic Status, Social Support, Self-efficacy and Well-being, Open Journal of Social Sciences.

Cohen, S., \& Syme, L. (1985). Issues in the study and application of social support. In S. Cohen \& S. L. Syme (Eds.), Social support and health. San Francisco: Academic Press.

Cummins, R. A. (1998).The Second Approximation to an International Standard for Life Satisfaction. Social Indicators Research, 43.

Davis, M. H., Morris, M. M., \& Kraus, L. A. (1998). Relationship-specific and global perceptions of social support: Associations with well-being and attachment. Journal of Personality and Social Psychology, 74(2), 468-481. http://dx.doi.org/10.1037//0022-3514.74.2.468

Diener, E., \& Chan, M. Y. (2011). Happy people live longer: Subjective well-being contributes to health and longevity. Applied Psychology: Health and Well-Being, 3(1), 1-43. http://dx.doi.org/10.1111/j.1758-0854.2010.01045.x

Diener, E., \& Ryan, K. (2009). Subjective well-being: A general overview. South African Journal of Psychology, 39(4), 391-406. http://dx.doi.org/10.1177/008124630903900402

Diener, Ed, Diener, M., \& Diener, C. (1995). Factors Predicting the Subjective Well-Being of Nations. Journal of Personality and Social Psychology, 69(5). http://dx.doi.org/10.1037/0022-3514.69.5.851

Diener, Ed., \& Fujita, F. (1995). Resources, Personal Strivings and Subjective Well-Being: A Nomothetic and Idiographic Approach. Journal of Personality and Social Psychology, 68(5). http://dx.doi.org/10.1037//0022-3514.68.5.926

Duncan O. D. (1961). A socio-economic index for all occupation and Properties and characteristics of the socioeconomic index. Occupations and Social Status [ M] . Glencoe: Free Press.

Gençöz, T., Özlale, Y., \& Lennon, R. (2004). Direct and indirect effects of social support on psychological well-being. Social Behavior and Personality: An International Journal, 32(5), 449-458. http://dx.doi.org/10.2224/sbp.2004.32.5.449

George, L. K., Okun, M., \& Landerman, R. (1985). Age as moderator of the determinants of life satisfaction [J]. Research on Aging, 7, 209-233. http://dx.doi.org/10.1177/0164027585007002004

Graham, C. (2005). Insights on development from the economics of happiness[J]. World Bank Research, 20, 201-231. http://dx.doi.org/10.1093/wbro/lki010

Green, L. W. (1970). Manual for scoring socioeconomic status for research on health behavior [J]. Public Health Reports, 85(9), 815-827. http://dx.doi.org/10.2307/4593972

Haller, A. O., \& Portes, A. (1973). Status attainment process [J] .Sociology of Education, 46, 51-91. http://dx.doi.org/10.2307/2112205

Han, J., Chu, X. Y., Song, H. C., \& Li, Y. (2014) Social Capital, Socioeconomic Status and Self-efficacy. Applied Economics and Finance, 1(2), 1-10 http://dx.doi.org/10.11114/aef.v2i1.607

Hayo, B. (2003). Happiness in Eastern Europe. Paper Presented at 5th Conference ISQOLS. Frankfurt, Germany. http://dx.doi.org/10.2139/ssrn.601201

Headey, B., \& Wearing, A. (1992). Understanding Happiness: A Theory of Subjective Well-Being. Melbourne: Longman Cheshire.

Hollingshead, Two factor index of social position [R] . (1957). New Haven : Department of Socio log y, Yale University .

Kahn, J. H., Hessling, R. M., \& Russell, D. W. (2003). Social support, health, and well-being among the elderly: what is the role of negative affectivity? Personality and Individual Differences, 35(1), 5-17. http://dx.doi.org/10.1016/s0191-8869(02)00135-6

King, L. A., \& Napa, C. K. (1998). What Makes a Life Good? Journal of Personality and Social Psychology, 75(1), 156-165. http://dx.doi.org/10.1037//0022-3514.75.1.156 
Kuppuswamy, B. (1981).Manual of socioeconomic status (urban) [M] New Delhi: Manasayan, 28.

Lancee, B. (2010). The economic returns of immigrants' bonding and bridging social capital: The case of the Netherlands. International Migration Review, 44(1), 202-226. http://dx.doi.org/10.1111/j.1747-7379.2009.00803.x

Lease, S. H., \& Dahlbeek, D. T. (2009). Parental influences, career decision-making attributions, and self-efficacy: Differences for men and women? Journal of Career Development, 36, 95-113. http://dx.doi.org/10.1177/0894845309340794

Liu, W. M., \& Wu, D. (2011). Education and Well-being. Science \& Technology Association Forum, 5

Lowry, J. H. (1984). Life satisfaction time components among the elderly [J]. Research on Aging, 6(3), 417-431. http://dx.doi.org/10.1177/0164027584006003007

Luo, C. L.(2006). Education, Income and Happiness, Journal of Technology College Education, 1.

Martin, P., Silvia, S. (2000). Influence of socioeconomic status, social network, and competence on Subjective wellbeing in later life: A meta- analysis[J] . Psychology and Aging, 15(2), 187-224. http://dx.doi.org/10.1037/0882-7974.15.2.187

Nahum-Shani, I., Bamberger, P. A., \& Bacharach, S. B. (2011). Social support and employee well-being: The conditioning effect of perceived patterns of supportive exchange. Journal of Health and Social Behavior, 52(1), 123-139. http://dx.doi.org/10.1177/0022146510395024

Ng, Y. K. (1997). A Case for Happiness, Cardinalsim, and Interpersonal Comparability. The Economic Journal 107(445),1848-1858. http://dx.doi.org/10.1111/j.1468-0297.1997.tb00087.x

Oakesa, J. M., \& Rossib, P. H. (2003).The measurement of SES in health research: current practice and steps toward a new approach[J]. Social Science \& Medicine, 56, 769-784. http://dx.doi.org/10.1016/s0277-9536(02)00073-4

Ryan, T.,\& Colleen, J. (2008). The relation of economic status to subjective well- being in Developing countries:A Meta- Analysis[J]. Psychology Bulletin, 134(4), 536-560. http://dx.doi.org/10.1037/0033-2909.134.4.536

Schyns, P. (1998). Crossnational Differences in Happiness. Social Indicators Research, 43.

Silverstein, M., \& Bengtson, V. L. (1994). Does intergenerational social support influence the psychological well-being of older parents? The contingencies of declining health and widowhood. Social Science \& Medicine, 38(7), 943-957. http://dx.doi.org/10.1016/0277-9536(94)90427-8

Taylor, S. E. (2011). Social support: A review. In M. S. Friedman (ed.), The handbook of health psychology (pp. 189-214). New York: Oxford University Press.

Tiwari, S. C, Kumar, A., \& Kumar A. (2005). Development and standardization of a scale to measure socio- economic status in urban and rural communities in India [J]. Indian J Med Res, 122, 309-314.

Warner. (1949). Social Class in America [R]. Chicago: Science Research Associates. http://dx.doi.org/10.2307/2571673

\section{(cc) $\mathrm{BY}$}

This work is licensed under a Creative Commons Attribution 3.0 License. 